\title{
Corticosteroids and azathioprine do not prevent radiation-induced lung injury
}

\author{
Eva Kwok MD, Charles K Chan MD FRCPC FCCP FACP \\ Division of Respiratory Medicine, Department of Medicine, the Toronto Hospital and the \\ Princess Margaret Hospital, University of Toronto, Toronto, Ontario
}

\begin{abstract}
E Kwok, CK Chan. Corticosteroids and azathioprine do not prevent radiation-induced lung injury. Can Respir J 1998;5(2):211-214.
\end{abstract}

The case of a man who presented with dyspnea and a dry cough six weeks after mediastinal radiotherapy for malignant thymoma is described. The patient was on prednisone (30 $\mathrm{mg}$ /day) and azathioprine $(100 \mathrm{mg} /$ day $)$ throughout the course of radiation. The respiratory difficulties developed as the dose of prednisone was gradually decreased to $20 \mathrm{mg} / \mathrm{day}$ postradiation. Chest x-ray showed bilateral pulmonary infiltrates. Computed tomography scan of the thorax confirmed bilateral ground glass opacities, with well-defined lateral margin on the right side corresponding to the field of radiation. However, the airspace opacities extended beyond the radiation field into the periphery of the lungs together with mild airway dilation on the left side compatible with bronchiolitis obliterans organizing pneumonia (BOOP) or cryptogenic organizing pneumonia. Bronchoalveolar lavage performed on the nonirradiated area showed an intense lymphocytosis. No cause of BOOP other than radiation was found. Treatment with high dose corticosteroids $(80 \mathrm{mg} /$ day $)$ resulted in rapid clinical and radiological improvement, and resolution of chest $\mathrm{x}$-ray abnormalities. Focal mediastinal radiation therapy may induce diffuse lung injury including BOOP. In addition, the concurrent use of moderate dose prednisone and azathioprine during the periradiotherapy period does not prevent the development of either BOOP or classic radiation pneumonitis.

Key Words: Bronchiolitis obliterans organizing pneumonia, Cryptogenic organizing pneumonia, Radiation pneumonitis

\section{Les corticostéroïdes et l'azathioprine ne pré- viennent pas une pneumopathie radique}

RÉ.SUMÉ : Le cas d'un homme qui s'est présenté avec une dyspnée et une toux sèche six semaines après une radiothérapie médiastinale pour un thymome malin est décrit. Le patient a pris de la prednisone (30 mg/jour) et de l'azathioprine (100 mg/jour) pendant toute la durée de la radiothérapie. Les troubles respiratoires sont apparus lors d'une réduction progressive de la dose de prednisone jusqu'à 20 mg/jour après les radiations. La radiographie pulmonaire a révélé des infiltrats pulmonaires bilatéraux. Une tomodensitométrie du thorax a confirmé la présence d'opacités en verre dépoli, avec une marge latérale bien définie sur le côté droit correspondant au champ des radiations. Cependant, les opacités alvéolaires s'étendaient au-delà du champ des radiations jusqu'en périphérie des poumons accompagnées d'une légère dilatation des voies aériennes sur le côté gauche compatible avec une bronchiolite oblitérante avec pneumonie en voie d'organisation (BOOP) ou une pneumonie cryptogénique en voie d'organisation. Un lavage broncho-alvéolaire pratiqué dans la partie non irradiée a révélé une lymphocytose importante. Aucune autre cause pour la BOOP que les radiations n'a été trouvée. Un traitement avec des fortes doses de corticostéroïdes (80 mg/jour) a entraîné une amélioration clinique et radiologique rapide, et une résolution des anomalies de la radiographie pulmonaire. La radiothérapie médiastinale focale peut induire une atteinte pulmonaire diffuse y compris une BOOP. De plus, l'usage concomitant d'une dose modérée de prednisone et d'azathioprine pendant la période de la radiothérapie ne prévient pas le développement d'une BOOP ou d'une pneumopathie radique classique. 
$\mathrm{R}$ adiotherapy in the treatment of malignant disease in the thorax is well recognized as a potential cause of lung injury in the form of acute pneumonitis and fibrosis. Classically, the acute onset of radiation pneumonitis occurs four to 12 weeks after completion of radiotherapy, with chronic radiation fibrosis occurring more than nine months after treatment (1). Lesions are almost exclusively confined to the radiation port. However, descriptions of bilateral pulmonary reaction that followed unilateral irradiation have recently been reported $(2,3)$. In addition, radiation injury may cause a clinicopathological syndrome similar to idiopathic bronchiolitis obliterans organizing pneumonia (BOOP; synonym cryptogenic organizing pneumonitis) (3-6).

\section{CASE PRESENTATION}

The patient, a 68-year-old exsmoker, underwent thymectomy in May 1995 for myasthenia gravis. During surgery, the thymoma was found to be malignant. After surgery, he received radiation to his mediastinal area at $200 \mathrm{cGy} /$ day for 20 days. The patient was maintained on azathioprine $100 \mathrm{mg} /$ day and prednisone $30 \mathrm{mg} /$ day throughout his radiation treatment, and pyridostigmine $60 \mathrm{mg}$ three times/day for myasthenia gravis. He did not receive chemotherapy. There was no exposure to inhaled allergens or toxins, history of systemic disease, preceding upper respiratory infection or other neoplastic disease.

Six weeks after the completion of radiation therapy, the patient developed progressive dyspnea on exertion and a dry cough. He had no sputum production, hemoptysis fever or chills. The respiratory symptoms developed as the dose of prednisone was gradually reduced at a rate of $5 \mathrm{mg} /$ day/month to $20 \mathrm{mg} /$ day. Chest x-ray showed no evidence of parenchymal disease. Treatment with trimethoprim/sulfamethoxazole and cough suppressant was initiated with no clinical im- provement. The patient was admitted to hospital five days later with worsening dyspnea and cough.

On admission pulse rate was 84 beats/min, blood pressure was $130 / 80 \mathrm{mmHg}$, respiratory rate was 16 breaths/min, and the patient was afebrile. Bibasilar inspiratory crackles were noted, and breath sound was good bilaterally. There was no evidence of clubbing or lymphadenopathy. Cardiovascular and abdominal examinations were both unremarkable.

Chest x-ray on admission showed coarse streaky opacities radiating out from the right hilum (Figure 1, left), with interval development of moderate left perihilar and mid lung opacities, in part airspace and in part reticular. Computed tomography (CT) of the thorax showed diffuse patchy ground glass opacities bilaterally, most prominent in the middle to upper lung zones, with mild airways dilation in these regions (Figure 2). On the right side, there was a well-defined sharp lateral margin to the opacities that coincided with the radiation port zone and was not explained by any anatomical boundary, compatible with radiation-induced acute lung injury. The margin on the left was ill-defined and tended to follow airways towards the periphery of the lungs. Appearance of the left lung was compatible with BOOP. There was a small right-sided pleural effusion and minimal left pleural reaction. There was no mediastinal lymph node.

Arterial blood gases drawn while breathing room air showed an arterial oxygen tension of $70 \mathrm{mmHg}$, arterial carbon dioxide tension of $30 \mathrm{mmHg}$, bicarbonate $22 \mathrm{mmol} / \mathrm{L}$ and $\mathrm{pH}$ 7.47. Hemoglobin was $123 \mathrm{~g} / \mathrm{L}$, white blood cell count was $10.5 \times 10^{9}$ cells $/ \mathrm{L}$ and platelet count was $226 \times 10^{9}$ platelets/L. Electrolytes, creatinine and urea were all within normal limits.

At bronchoscopy, both the proximal and distal airways were normal, and there was no pus. Bronchoalveolar lavage (BAL) was obtained from the lingula in the standard fashion

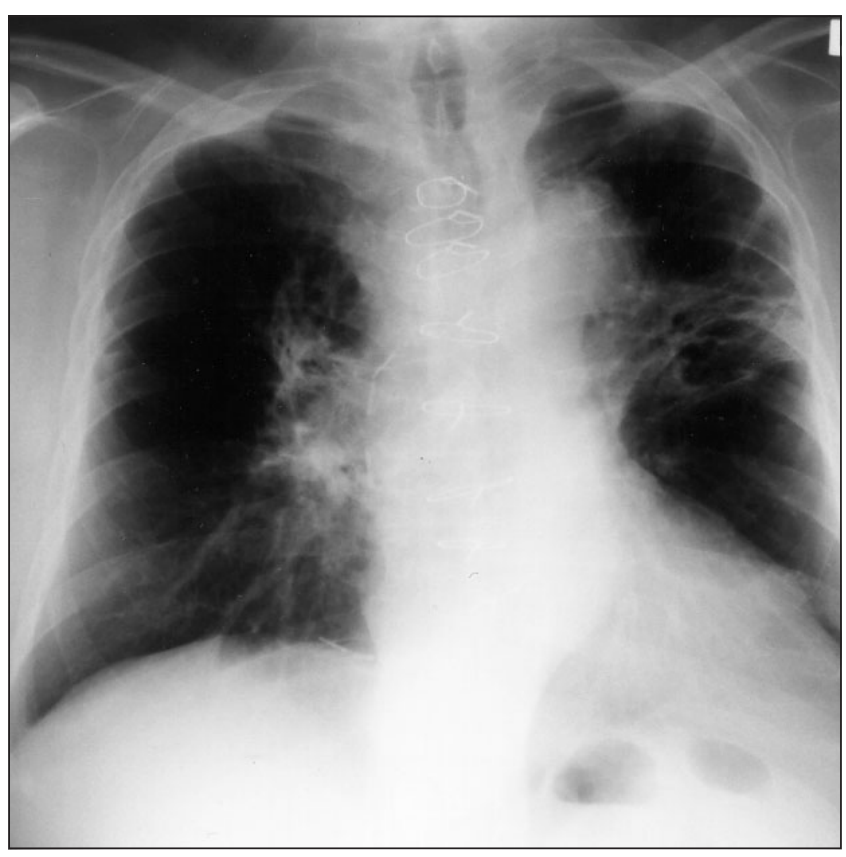

Figure 1) Left Right perihilar coarse streaky opacity and left mid-lung airspace and reticular opacities. Right Significant resolution of pulmonary infiltrates after five days of increased dose of prednisone 




Figure 2) Computed tomography of the thorax showing diffuse patchy ground glass opacities with mild airway dilation. A welldefined lateral margin is seen on the right. The infiltrates tend to follow the airways and extend to the periphery of the lung on the left

with five $20 \mathrm{~mL}$ aliquots of normal saline. A careful search for pathogens in the BAL was negative; in particular, acid fast bacilli stain, fungal and methenamine silver stain, and direct fluorescent antibody stain for cytomegalovirus were negative, and there were no viral cytopathic changes. Final cultures were all negative. Differential cell count from the BAL showed $40 \%$ macrophages, $4 \%$ neutrophils and $56 \%$ lymphocytes; lymphocyte subtyping was not done.

Treatment with a higher dosage of corticosteroids at $1 \mathrm{mg} / \mathrm{kg} /$ day resulted in rapid clinical improvement over several days and considerable improvement of the chest x-ray (Figure 1, right).

\section{DISCUSSION}

Radiation-induced injury of the lung is common after irradiation for carcinoma of the thorax. Typically, both the pathological and radiological changes are confined to the outline of the radiation fields. There are two well-describe, $\mathrm{d}$ distinct clinical phases: acute pneumonitis occurring about four to 12 weeks after completion of radiotherapy, and pulmonary fibrosis occurring more than nine months after treatment (1). The exact mechanism remains controversial, but classic radiation pneumonitis results from a dose-related pulmonary toxicity, with the inflammatory and fibrotic processes being mediated by locally released cytokines and growth factors. This mechanism of lung injury involves direct tissue damage from radiotherapy, and is generally confined to the outline of the radiation field.

Bilateral pulmonary reactions in patients undergoing unilateral irradiation have also been reported, with BAL showing a picture predominantly of lymphocytic alveolitis of the CD4 type (2,3). This suggests that, other than direct doserelated toxicity, there must be another mechanism, likely immunologically mediated, that causes a picture similar to hypersensitivity pneumonitis postradiotherapy. Radiation might induce the activation of pulmonary lymphocytes that recognize autoantigens released and unmasked after the initially local lung tissue damage $(2,3)$.

By contrast, BOOP is a very uncommon finding after radiation exposure. Two previous cases have been reported in the literature; both were limited to the irradiated area $(4,5)$. One occurred two months after and the other 13 years after completion of irradiation. Recently five more cases of migrating BOOP two to seven months postradiotherapy for breast carcinoma have been reported (6-8). In all five cases of BOOP, there was bilateral lung disease despite a unilateral lung field irradiation, and in one of the cases, BAL demonstrated classical CD8 lymphocytosis of BOOP (9).

Our patient presented with clinical, imaging and $\mathrm{BAL}$ findings consistent with BOOP (9-13) on the nonirradiated side of the chest. Although we do not have the subset differential counts of the BAL cells or tissue biopsy, the CT scan findings are more compatible with BOOP than with hypersensitivity pneumonitis. We believe radiation was a cause of BOOP in this case for three reasons. First the temporal relationship fit with the usual reported delay in the onset of a radiation-triggered alveolitis after the period of irradiation. Second, there was simultaneous evidence of classic radiation pneumonitis within the irradiated field of the chest. Third, no other cause of BOOP was identified.

Our patient is unique because of the simultaneous presence of both classic radiation pneumonitis within the irradiated field and the development of BOOP on the nonirradiated side. Of note is that the five recent cases of radiation-related BOOP occurred in patients with breast carcinoma $(6,7)$; our patient demonstrates that this may happen in patients with malignant thymoma as well, indicating that the type of preceding malignancy probably plays no role in the pathogenesis of radiation-induced BOOP.

Our patient was on long term moderate doses of prednisone and azathioprine throughout the radiation treatment. Despite being on two immunosuppressive medications, both BOOP and classic radiation pneumonitis developed with clinical deterioration. Both prednisone and azathioprine have been used as treatment for radiation pneumonitis (14), but there are no published studies assessing the effectiveness of corticosteroids or azathioprine as prophylaxis against radiation-induced pneumonitis. Rats treated with steroids after radiotherapy show suppression of alveolitis provided steroids are used throughout the period of radiation; tissue mast cell response to radiation is also delayed, but the development of fibrosis is not altered (15). In humans, however, as our case demonstrates that moderate doses of corticosteriods and azathiorprine are not effective as prophylaxis against either BOOP or classic radiation pneumonitis.

Despite the failure of prednisone and azathioprine to prevent radiation pneumonitis and BOOP, a higher dosage of prednisone at $1 \mathrm{mg} / \mathrm{kg} /$ day did result in significant clinical improvement and resolution of chest $\mathrm{x}$-ray abnormalities. This suggests that BOOP resulting from radiation therapy is comparable with BOOP caused by other etiologies and that it can be treated with high dose corticoster- 
oids. Prompt recognition and correct diagnosis is, therefore, crucial for early treatment and prevention of disease progression.

\section{REFERENCES}

1. Davis SD, Yankelevitz DH, Henschke CI. Radiation effects on the lung: clinical features, pathology and imaging findings. Am J Roentgenol 1992;159:1157-64.

2. Roberts CM, Foulcher E, Zaunders JJ, et al. Radiation pneumonitis: A possible lymphocyte-mediated hypersensitivity reaction. Ann Intern Med 1993;118:696-700.

3. Gibson PG, Bryant DH, Morgan GW, et al. Radiation-induced lung injury: a hypersensitivity pneumonitis? Ann Intern Med 1988:109:288-91.

4. Kaufman J, Komorowski R. Bronchiolitis obliterans: A new clinical-pathologic complication of irradiation pneumonitis. Chest 1990;97:1243-4.

5. Tobias ME, Plit M. Bronchiolitis obliterans organizing pneumonia with migratory infiltrates: a late complication of radiation therapy. Am J Roentgenol 1993;160:205-6.

6. Crestani B, Kambouchner M, Soler P, et al. Migratory bronchiolitis obliterans organizing pneumonia after unilateral radiation therapy for breast carcinoma. Eur Respir J 1995;8:318-21.
7. Bayle JY, Nesme P, Bejui-Thivolet F, Loires R, Guerin JC, Cordier JF. Migratory cryptogenic organizing pneumonitis 'primed' by radiation therapy. Eur Respir J 1995;8:322-6.

8. Van Laar JM, Holscher HC, Van Krieken JHJM, Stolk J. Bronchiolitis obliterans organizing pneumonia after adjuvant radiotherapy for breast carcinoma. Respir Med 1997;91:241-4.

9. Nagai S, Aung H, Tanaka S, et al. Bronchoalveolar lavage cell findings in patients with bronchiolitis obliterans organizing pneumonia and related diseases. Chest 1992;102(1 Suppl):32S-7S.

10. Costabel U, Teschler H, Schoenfeld B, et al. BOOP in Europe. Chest 1992;102(1 Suppl):14S-20S

11. Morgan GW, Pharm B, Breit SN. Radiation and the lung: A reevaluation of the mechanisms mediating pulmonary injury. Int J Radiat Oncol Biol Phys 1995;31:361-9.s

12. Nishimura K, Itoh H. High-resolution computed tomographic features of bronchiolitis obliterans organizing pneumonia. Chest 1992;102 (1 Suppl):26S-31S

13. Epler GR. Bronchiolitis obliterans organizing pneumonia: Definition and clinical features. Chest 1992;102(1 Suppl):2S-6S.

14. McCarty MJ, Lillis P, Vukelja SJ. Azathioprine as a steroid-sparing agent in radiation pneumonitis. Chest 1996;109:1397-400.

15. Ward HE, Kemsley L, Davies L, Holecek M, Berend N. The effect of steroids on radiation-induced lung disease in the rat. Radiat Res 1993; 136:22-8. 


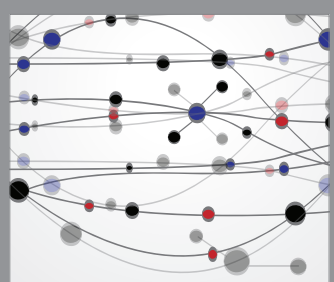

The Scientific World Journal
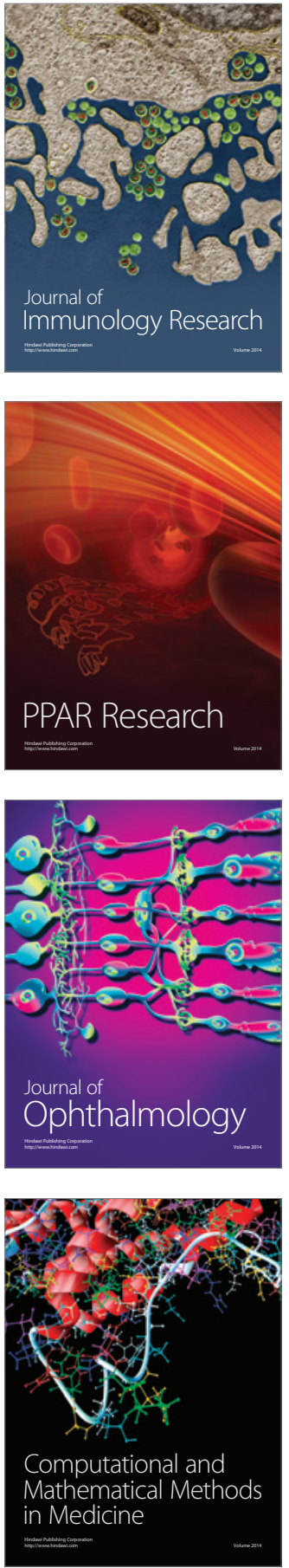

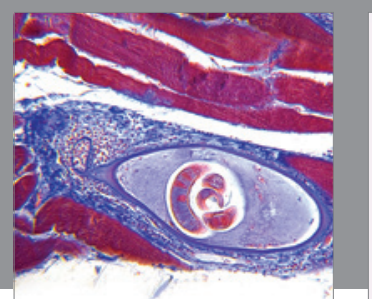

Gastroenterology Research and Practice

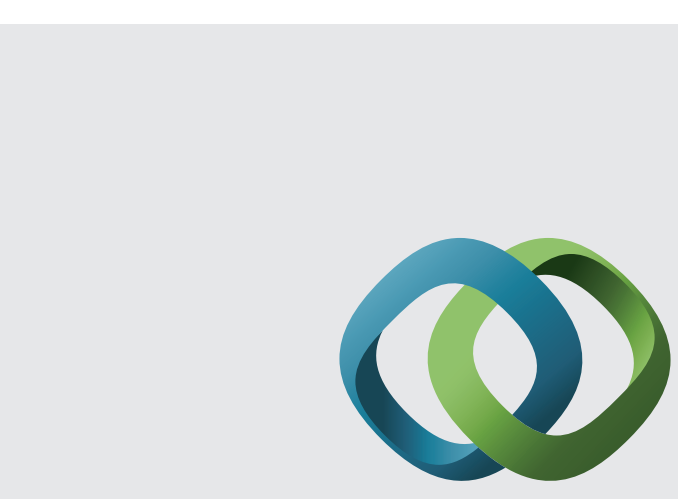

\section{Hindawi}

Submit your manuscripts at

http://www.hindawi.com
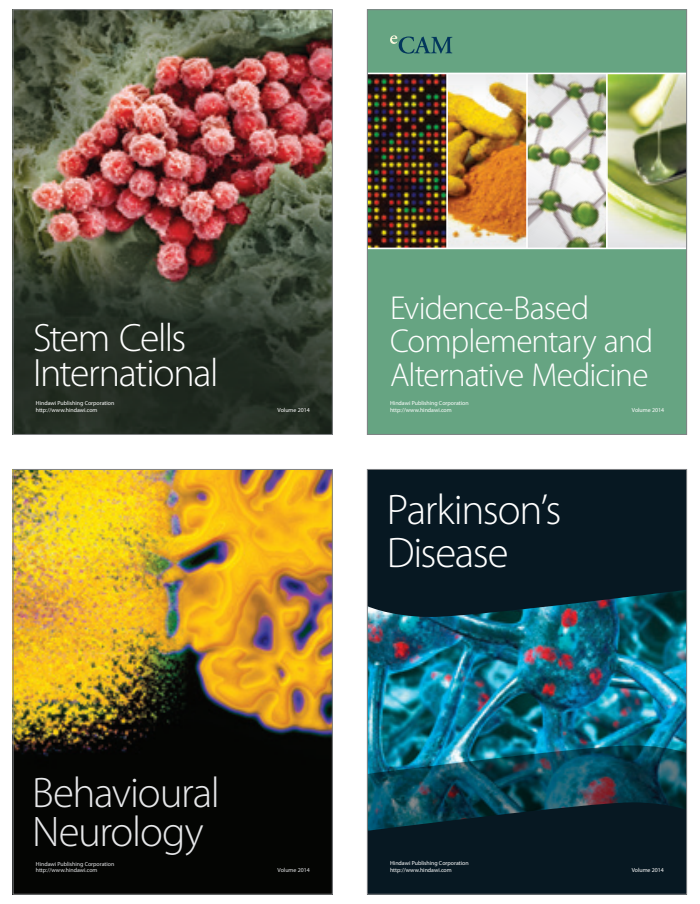
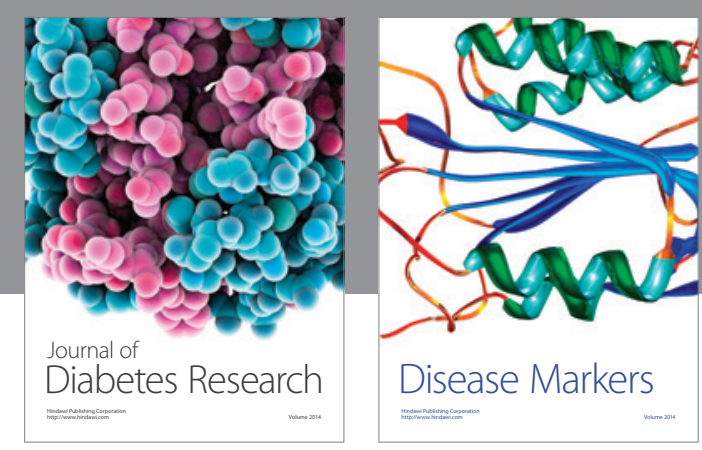

Disease Markers
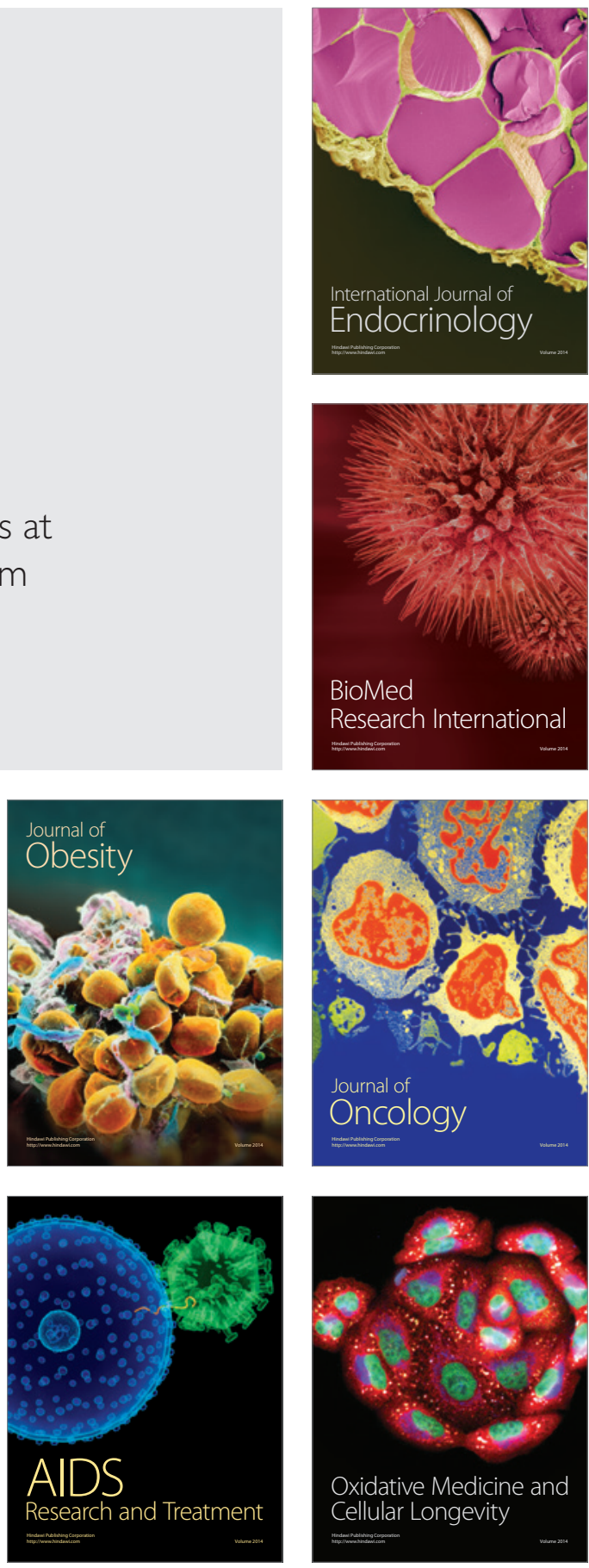